\title{
Emerging oral treatments in multiple sclerosis - clinical utility of cladribine tablets
}

This article was published in the following Dove Press journal:

Therapeutics and Clinical Risk Management

28 August 2010

Number of times this article has been viewed

\author{
Claudio Gasperini' \\ Serena Ruggieri ${ }^{2}$ \\ Carlo Pozzilli² \\ 'Department of Neurosciences, \\ S Camillo Forlanini Hospital, Rome, \\ Italy; ${ }^{2}$ Department of Neurological \\ Sciences, University of Rome \\ "La Sapienza”, Italy
}

\begin{abstract}
Multiple sclerosis (MS) is a chronic inflammatory disorder of the central nervous system (CNS) that represents one of the first causes of neurological disability in young adults. Although the pathogenesis of MS is still unclear, an autoimmune mechanism has been demonstrated. According to this evidence in the last 15 years different treatments acting on the immune system have been developed. Current disease-modifying drugs (DMDs) for MS require regular and frequent parenteral administration and are associated with limited long-term treatment adherence. Moreover the clinical efficacy of these disease-modifying drugs is suboptimal. Thus, there is an important need for the development of new therapeutic strategies. Several oral therapies (fingolimod, fumaric acid, teriflunomide, laquinimod) are in development; Among these cladribine is the only therapy with the potential for short-course dosing. Cladribine is an immunosuppressant that offers sustained regulation of the immune system through a preferential lymphocyte depleting action. Cladribine has a well-characterized and well-known safety profile, derived from more than 15 years of use of the parenteral formulation both in the oncology field and in MS. This paper reviews the new oral emerging treatments and presents the available data about the use of cladribine in MS and the future perspective of its clinical use.
\end{abstract}

Keywords: multiple sclerosis, disease modifying drugs, oral therapy, treatment adherence, cladribine

\section{Introduction}

Multiple sclerosis (MS) is a chronic inflammatory disease of the central nervous system (CNS) that can lead to severe disability in many young adult patients, and is one of the most common causes of neurological disability in this population. ${ }^{1}$ In this inflammatory and neurodegenerative disorder, autoreactive immune cells, cytokines, macrophages, and antibodies attack myelin sheaths and injure underlying axons. The accumulation of axonal damage leads to permanent loss of neurological function. ${ }^{2}$ The disease course varies among patients: most patients present initially with relapsing-remitting (RR) MS, in which partial or complete recovery from neurological function occurs during periods of remission. ${ }^{3}$ However a large proportion of patients (approximately half) subsequently develop secondary progressive (SP) MS, in which disability continues to accumulate irrespective of relapse activity and few effective therapies could be used apart from symptomatic ones. ${ }^{4}$ Early recognition and treatment of MS to reduce the risk and to mitigate the severity of relapses has the potential to forestall the accrual of disability. ${ }^{5}$

The past 15 years have witnessed the introduction of several therapies for MS. Treatment of RRMS typically consists of direct symptom management, brief corticosteroid administration for acute exacerbations, and the regular use of disease modifying
Correspondence: C Gasperini

Dipartimento Testa Collo,

Azienda Ospedaliera S Camillo-

Forlanini, Circonvallazione Gianicolense,

87,00152 Rome, Italy

Tel +39658704272

Fax +39658704650

Email c.gasperini@libero.it 
drugs (DMDs). Currently approved immumomodulator treatments for RRMS include glatiramer acetate (GA) and recombinant interferons (IFN $\beta$ ) (IFN $\beta$-1a Avonex ${ }^{\circledR}$, IFN $\beta$-1a Rebif $^{\circledR}$, IFN $\beta-1 b$ Betaseron ${ }^{\circledR}$, Extavia $^{\circledR}$ ) that represent the gold standard in modifying the course of MS. Natalizumab (Tysabri $^{\circledR}$ ) and mitoxantrone $\left(\right.$ Novantrone $^{\circledR}$ ) are also available for treatment of MS as second line therapy. Nevertheless, in clinical practice DMDs or immunosuppressive treatments are frequently associated with suboptimal response in terms of efficacy. It has been demonstrated that a proportion of patients treated with interferons develop neutralizing antibodies during their therapy, although this only partially explains the suboptimal response to IFN $\beta$ treatment. ${ }^{6}$ Patients treated with interferons often experience several side effects such as flu-like symptoms and injections side reactions that can frequently lead to poor patient adherence. These DMDs for MS require long term, regular injection or monthly parenteral infusions, which may be uncomfortable and inconvenient for the patient. This may affect adherence and could easily lead to patients dropping out of therapy. ${ }^{7}$ Thus there is an important need for new therapeutic strategies, especially those that may offer greater patient satisfaction in order to optimize therapeutic outcomes. Currently there are more than 30 compounds which have already been tested or are awaiting Phase II studies in MS. ${ }^{8}$ Phase III studies with cladribine tablets have been completed, and following marketing authorization application cladribine could become the first orally administered DMD for patients with RRMS. Here, we review oral compounds that have successfully completed their first clinical trials, focusing on cladribine tablets and its expected impact on clinical practice.

\section{Oral MS therapies in development}

A number of potential therapies for MS are now in late-stage development. To improve patient compliance with treatment and reduce lack of adherence, most of these are oral compounds and include: fingolimod (FTY720), fumaric acid (BG12), teriflunomide (A77126 or HMR1726) and laquinimod (ABR-215062).

Fingolimod is a structural analogue of sphingosine that interferes with cell traffic between organs and blood. In a 6-month placebo controlled Phase II study in 281 patients with RRMS oral fingolimod at doses of 1.25 and $5 \mathrm{mg}$ significantly reduced inflammatory disease activity as measured by magnetic resonance imaging (MRI) (up to $80 \%, P<0.001$ for the higher dose) and clinical relapse rate by more than $50 \%$ (6-month annualized relapse rate of $0.35-0.36$ with fingolimod for the two doses vs 0.77 with placebo; $P \leq 0.01$ for both doses). ${ }^{9}$ Common side effects included dose-dependent transient arrhythmias within hours of the first dose, increased mean arterial blood pressure, and airway obstruction.

Patients who received the higher dose of fingolimod $(5 \mathrm{mg}$ ) had more frequent upper respiratory tract infections than patients who received the lower dose $(1.25 \mathrm{mg})$ or placebo. In view of the frequency and severity of the side effects observed in the high-dose group ( $5 \mathrm{mg}$ ), a Phase III study assessing the efficacy of the $1.25 \mathrm{mg}$ dose and a lower dose of $0.5 \mathrm{mg}$ has been developed in RRMS patients. The FTY720 Research Evaluating Effects of Daily Oral Therapy in Multiple Sclerosis (FREEDOMS) study demonstrated that the aggregate annualized relapse rate (the primary endpoint) was lower with fingolimod at a dose of $0.5 \mathrm{mg}(0.18)$ and with fingolimod at a dose of $1.25 \mathrm{mg}(0.16)$ than with placebo (0.40), representing relative reductions of $54 \%$ and $60 \%$, respectively, in the annualized relapse rate $(P<0.001)$. The time to disability progression, with confirmation either after 3 months (the key secondary end point) or after 6 months, was longer with both fingolimod doses than with placebo, as also were MRI-related end points expressed as the number of gadolinium (Gd)-enhancing lesions at 24 months and an absence of Gd-enhancing lesions at 24 months - both $P<0.001$. $^{10}$

Moreover a 12-month, double-blind, double-dummy study in which 1292 patients with relapsing-remitting multiple sclerosis who had a recent history of at least one relapse were randomly assigned to receive either oral fingolimod at a daily dose of either 1.25 or $0.5 \mathrm{mg}$ or intramuscular IFN $\beta-1 \mathrm{a}$ $\left(\right.$ Avonex ${ }^{\circledR}$ ) at a weekly dose of $30 \mu \mathrm{g}$ to evaluate the comparison in terms of relapse rate and MRI outcomes eg, new or enlarged lesions on T2-weighted images, or gadolinium (Gd)enhancing lesions on T1-weighted images. MRI measurement used to compare the two drugs showed a consistent result of the superior efficacy of oral fingolimod. ${ }^{11}$

Fumaric acid (FA) is an unsaturated dicarboxylic acid, isomeric to maleic acid, which acts as an intermediate in the Krebs cycle. Its exact mechanism of action is still unclear, but it appears to induce depletion of peripheral blood leukocytes owing mainly to a reduction in the number of T cells. In vitro studies indicate that fumaric acid esters (FAEs) induce a shift from Th1 to Th2 cytokines as part of their treatment effect. ${ }^{12}$ In an open label prospective study involving 10 patients with RRMS, FA produced significant reductions from baseline in the number $(P<0.05)$ and volume $(P<0.01)$ of Gd-enhancing lesions after 18 weeks of treatment at a target dose of 720 $\mathrm{mg}$ /day; this effect persisted through the second 48 -week treatment phase at half the target dose, following a 4-week 
washout period. ${ }^{13}$ In a 24-week, double-blind, randomized, placebo-controlled Phase IIb study in RRMS patients $(n=257)$, MRI analysis revealed a significant and dose-dependent reduction of brain lesion activity, particularly after treatment with the 720-mg dosage. In comparison to placebo, this group demonstrated $\sim 70 \%$ reduction in Gd-enhancing lesions and a 50\% reduction in new or enlarging $\mathrm{T} 2$ lesions and new $\mathrm{T} 1$ hypointense lesions. ${ }^{14}$ The most commonly observed adverse events (AE)s were flushing, nasopharyngitis, headache, nausea, diarrhea, fatigue, pruritus, upper abdominal pain, and hot flush, with evidence of a dose-related influence on the frequency of most of these AEs.

Teriflunomide is the active metabolite of leflunomide. Leflunomide blocks de novo pyrimidine synthesis by inhibiting dihydro-orotate dehydrogenase in T-cell and other rapidly dividing cell populations, leading to a decrease in DNA synthesis. ${ }^{15}$ Leflunomide is licensed for the treatment of rheumatoid arthritis and is also effective in experimental autoimmune neuritis and rat experimental autoimmune encephalomyelitis (EAE). ${ }^{16-17}$ A recent randomized, double-blind, placebo-controlled, parallelgroup trial assessed the safety and efficacy of this new drug on MS: 179 patients (157 with RRMS, 29 with SPMS) have been treated with placebo $(\mathrm{n}=61)$, teriflunomide $7 \mathrm{mg} /$ day $(\mathrm{n}=61)$, or teriflunomide $14 \mathrm{mg} /$ day $(\mathrm{n}=57)$ for 36 weeks. Treatment with teriflunomide 7 or $14 \mathrm{mg}$ /day resulted in the significant suppression of $>61 \%$ of MRI activity relative to placebo $(P<0.03$ at the dosage of $7 \mathrm{mg} /$ day and $P<0.001$ at the dosage of $14 \mathrm{mg} /$ day). The annualized relapse rate between placebo and teriflunomide $14 \mathrm{mg}$ /day was similar to that reported for IFN $\beta$ and GA (32\%). The higher dose of teriflunomide (14 mg/day) appears to be more effective than the $7 \mathrm{mg}$ /day dose, in terms of relapse rate, although no dose effect was observed on primary endpoints such as Gd-enhancing lesions and new/enlarging T2 lesions. ${ }^{18}$ AEs reported more frequently in the treatment groups than in the placebo group were: neutropenia, nasopharyngitis, alopecia, nausea, increase in alanine aminotransferase, paresthesia, back and limb pain, diarrhea and arthralgia. Combination studies of teriflunomide with IFN $\beta$ or GA and a trial investigating teriflunomide in clinically isolated syndrome are underway.

Laquinimod is a novel synthetic compound with oral bioavailability, that is in development as an oral formulation for the treatment of MS. Laquinimod was effective in a rat model of EAE, in which its efficacy was ascribed to modulation of the balance of the T-helper (Th) cells 1 and 2 induction of transforming growth factor $\beta .{ }^{19}$ However, the exact mechanism of action in MS patients is still ambiguous.
The efficacy of laquinimod was studied in two phase II studies. ${ }^{20}$ The first phase II clinical trials showed inconclusive results on the effect of a $0.3 \mathrm{mg}$ dose and led to further exploration of the therapeutic dose in an additional phase IIb study. The second study was a phase IIb, multinational, randomized, double-blind, parallel-group, placebo-controlled 36-week study, evaluating the efficacy, tolerability and safety of two daily oral doses (0.3 and $0.6 \mathrm{mg})$ of laquinimod (as compared to placebo) in subjects with RRMS. A total of 306 patients were randomized, with 98 subjects assigned to laquinimod $0.3 \mathrm{mg}, 106$ to laquinimod $0.6 \mathrm{mg}$, and 102 to placebo. The statistical analysis on the intention-to-treat (ITT) population for the primary endpoint demonstrated a statistically-significant treatment effect of laquinimod $0.6 \mathrm{mg}$ compared to placebo $(P=0.0048)$, with a reduction of $40 \%$ in the cumulative number of Gd-enhancing lesions at weeks 24, 28, 32 and 36. A nonsignificant treatment effect of $8 \%$ was observed with laquinimod $0.3 \mathrm{mg}(P=0.6740)$. A statistically-significant reduction of treatment effect of laquinimod 0.6 compared to placebo was demonstrated for other MRI-related endpoints, defined in the protocol as secondary endpoints. ${ }^{20}$ Based on a thorough review of all laquinimod clinical data available to date, the primary safety concerns include potential hepatotoxicity and a possible proinflammatory effect. Four serious adverse event AEs (SAEs) were reported: pleuritis, Budd-Chiari syndrome, pituitary adenoma with hemorrhage and a possible diagnosis of Crohn's disease. Pharyngolaryngeal pain, dyspepsia and ankle edema were also observed. Laboratory abnormalities seen in Phase II laquinimod studies include elevated white blood count, elevated fibrinogen levels, a trend towards decreased hemoglobin, elevated liver enzymes and increased of amylase.

\section{Introduction to cladribine}

Cladribine (2-chloro-2'-deoxyadenosine [2-CdA]) is an adenosine deaminase-resistant purine nucleoside analogue that preferentially reduces lymphocyte subpopulations. The molecule was first investigated at the Scripps Research Institute (CA, USA) in the late 1970s for the treatment of lymphoid malignancies. Carson and colleagues discovered that a deficiency of adenosine deaminase led to accumulation of intracellular toxic deoxyadenosine nucleosides and their phosphorylated products within lymphocytes, and resulted in selective lymphopenia. ${ }^{21}$ Based on these results, synthesis of several purine analogues began, among which cladribine was the most potent, offering targeted, sustained regulation of the immune system. The cladribine prodrug enters cells via purine 
nucleoside transporters and once within the cell, undergoes initial phosphorylation by deoxycytidine kinase. ${ }^{22}$ Lymphocytes are particularly susceptible to the effects of cladribine because of their high intracellular ratio of deoxycytidine kinase to 5'-nucleotidase. The accumulation of cladribine nucleotides disrupts DNA synthesis and repair, and ultimately leads to sustained reduction in lymphocytes. Cladribine is able to cross the blood-brain barrier (BBB $)^{22}$ and is, therefore, likely to act on cells in both the periphery and CNS appearing to have a greater effect on $\mathrm{CD} 4+\mathrm{T}$ cells than the CD8+ T cell population. ${ }^{23}$ The parenteral formulation of cladribine has been used extensively for the reduction of aberrant lymphocyte populations in the hematological oncology setting. It is indicated for the treatment of hairy cell leukemia (HCL), and has been used in the treatment of several other leukemias and lymphomas. ${ }^{24}$ The sustained effects of cladribine treatment support the use of an annual, short-course dosing regimen. Furthermore, a preservation of cell types that are key to maintenance of innate immune function has been observed, which may explain the low number of infections that occurred following cladribine treatment despite a reduction in lymphocyte numbers. Since MS is known to be an autoimmune disease, parenteral cladribine was evaluated in Phase II/III clinical trials in patients with RRMS or progressive MS. ${ }^{23-25}$ Cladribine tablets were consequently developed.

\section{Clinical efficacy and safety profile of cladribine in MS Clinical trials}

Parenteral cladribine has been investigated for treatment efficacy in different autoimmune disorders, including MS, such as rheumatoid arthritis and systemic lupus erythematosusassociated glomerulonephritis. ${ }^{26}$ Current knowledge on the efficacy and safety of cladribine tablets in MS is based on data from the CLARITY study. This is supported by historical studies which evaluated parenteral cladribine in relapsing and progressive forms of MS. The key findings from these studies are summarized below (Table 1).

Three randomized, double-blind, parallel-group, placebocontrolled, phase II/III trials conducted at the Scripps Research Institute (Scripps-C, MS-Scripps and MS-001) have been performed in patients with MS to assess the efficacy and safety of cladribine. ${ }^{23-25}$ In the placebo-controlled phases of these studies, 183 patients received intravenous or subcutaneous cladribine, at doses of $0.7-2.8 \mathrm{mg} / \mathrm{kg}$, administered in monthly 5- to 7-day courses for 2-6 months, and were followed for up to 24 months. These studies showed statistically-significant improvement in MRI measures of activity (Table 1). In the 18-month (Scripps-C) study, 52 patients with RRMS received cladribine, $2.1 \mathrm{mg} / \mathrm{kg}$ subcutaneously (SC), or placebo, over 6 months, and were followed for a further 12 months. The primary endpoints of the study were the frequency and severity of the relapses and the number of Gd-enhancing lesions observed at MRI scan. A significant reduction in frequency and severity of relapses was observed in patients receiving cladribine compared with those receiving placebo from months $7-12(P=0.021)$, which was maintained at month $18(P=0.010)$. There was also a significant reduction in the occurrence of Gd-enhancing lesions at 12 months compared with placebo $(P=0.0001)$, which remained significant lower at 18 months $(P=0.002) .{ }^{27}$ Patients with primary or secondary progressive forms of MS, received parenteral cladribine in the 12-month MS-001 and 24-month treatment crossover MS-Scripps studies. ${ }^{25}$ In the MS-001 study cladribine led to a $>90 \%$ reduction in the mean number of T1 Gd-enhancing lesions at 6 months which was maintained throughout the study $(P \leq 0.005$ for the $0.7 \mathrm{mg} / \mathrm{kg}$ group and $P=0.001$ for the $2.1 \mathrm{mg} / \mathrm{kg}$ group, versus placebo at final evaluation) and $\mathrm{a}>90 \%$ reduction in mean volume of T1 Gd-enhancing lesions in both cladribine groups after 6 months, which was also maintained throughout the study $(P<0.001$ after 18 months and $P=0.007$ after 24 months vs placebo). No significant differences in primary clinical outcomes (mean change in Expanded Disability Status Scale [EDSS] score) were detected between patients in the cladribine groups and placebo, but a trend toward a later time to disability progression was found in cladribine-treated patients compared to placebo in the SPMS subgroup. The lack of effect of cladribine on the disability measures in contrast to its dramatic impact on MRI measures has been explained by the short duration of the trial and by the high baseline EDSS score (median 6.0) of the study population. ${ }^{25}$ Prior to treatment crossover in the MS-Scripps study (after 12 months), significantly fewer patients receiving cladribine $(2.8 \mathrm{mg} / \mathrm{kg})$ than placebo had Gd-enhancing lesions $(P<0.001)$. Furthermore there was an improvement in mean EDSS and Scripps Neurological Rating Scale (SNRS) scores $(P<0.01$ and $P<0.001$, vs placebo, respectively). However it must be considered that both primary and secondary progressive patients were included, so those results might be difficult to interpret.

Building on the experience with parenteral administration, short-course therapy with cladribine tablets was investigated for RRMS in the CLARITY study (CLAdRIbine Tablets treating multiple sclerosis orallY). ${ }^{28}$ CLARITY was a Phase III, randomized, double-blind, placebo-controlled, multicentre, 96-week study with three parallel groups to 
Table I Efficacy data from Phase II/III scripps studies of parenteral cladribine for $\mathrm{MS}^{23,24,35}$

\begin{tabular}{|c|c|c|c|}
\hline Study & $\begin{array}{l}\text { Dose regimen } \\
\text { (total dose) }\end{array}$ & MRI Gd+ lesions & Neurologic outcomes \\
\hline Scripps-C & $\begin{array}{l}0.07 \mathrm{mg} / \mathrm{kg} / \text { day SC } 5 \text { days } / \text { month } \\
\text { for } 6 \text { months }(2.1 \mathrm{mg} / \mathrm{kg})\end{array}$ & $\begin{array}{l}\text { Reduced number of } \\
\text { lesions at } 6 \text { and I } 2 \text { months } \\
\text { relative to baseline }(P<0.003 \\
\text { vs placebo) }\end{array}$ & $\begin{array}{l}\text { Reduced frequency } \\
\text { and severity of } \\
\text { relapses vs placebo }(P= \\
0.021)\end{array}$ \\
\hline MS-Scripps & $\begin{array}{l}\text { Year I: } 0.1 \mathrm{mg} / \mathrm{kg} / \text { day IV } 7 \text { days } \\
\text { for } 4 \text { months }(2.8 \mathrm{mg} / \mathrm{kg}) \text {; } \\
\text { Year } 2: 0.1 \mathrm{mg} / \mathrm{kg} / \text { day IV } 7 \text { days } \\
\text { for I month and } 0.05 \mathrm{mg} / \mathrm{kg} / \text { day } \\
\text { IV } 7 \text { days for } 2 \text { months }(1.4 \mathrm{mg} / \mathrm{kg})\end{array}$ & $\begin{array}{l}\text { Reduced proportion of } \\
\text { patients with lesions at } \\
\text { I } 2 \text { months compared } \\
\text { with placebo }(P<0.00 \text { I })\end{array}$ & $\begin{array}{l}\text { Improvement in mean } \\
\text { EDSS and SNRS } \\
\text { scores }(P<0.0 \text { I and } \\
P<0.00 \text { I vs } \\
\text { placebo, respectively })\end{array}$ \\
\hline MS-00I & $\begin{array}{l}0.07 \mathrm{mg} / \mathrm{kg} / \text { day SC } \\
5 \text { days } / \mathrm{month} \text { for } \\
6 \text { months }(2.1 \mathrm{mg} / \mathrm{kg}) ; \\
0.07 \mathrm{mg} / \mathrm{kg} / \text { day SC } \\
5 \text { days } / \mathrm{month} \text { for } \\
2 \text { months }(0.7 \mathrm{mg} / \mathrm{kg})\end{array}$ & $\begin{array}{l}\geq 90 \% \text { reduction in the } \\
\text { mean number of lesions } \\
\text { at } 6 \text { months and } \\
\text { maintained throughout } \\
\text { the study; } \\
(P \leq 0.005 \text { for } 0.7 \mathrm{mg} / \mathrm{kg} \\
\text { group and } P=0.00 \mathrm{I} \text { for } \\
2.1 \mathrm{mg} / \mathrm{kg} \text { group vs } \\
\text { placebo at final } \\
\text { evaluation) } \\
>90 \% \text { reduction in } \\
\text { mean volume of lesions } \\
\text { in both cladribine groups } \\
\text { after } 6 \text { months and } \\
\text { maintained throughout } \\
\text { the study ( } P<0.00 \mathrm{I} \\
\text { after } 18 \text { months and } \\
P=0.007 \text { after } 24 \text { months } \\
\text { vs placebo) }\end{array}$ & $\begin{array}{l}\text { No significant } \\
\text { differences in primary } \\
\text { clinical outcomes } \\
\text { (EDSS) between the } \\
\text { two groups; a trend } \\
\text { toward a later time to } \\
\text { disability progression } \\
\text { was found in } \\
\text { cladribine-treated } \\
\text { patients vs placebo in } \\
\text { the SPMS subgroup }\end{array}$ \\
\hline
\end{tabular}

Abbreviations: EDSS, expanded disability status scale; Gd+, gadolinium-enhancing; IV, intravenous; SC, subcutaneous; SNRS, scripps neurologic ratings scale.

assess the efficacy of cladribine tablets in patients aged 18-65 years with a diagnosis of RRMS according to the McDonald criteria. The primary endpoint of the study was to evaluate the efficacy of cladribine tablets versus placebo in reducing the relapse rate during 96 weeks of treatment. The dosing regimen for the cladribine tablets consisted of two or four short courses per year (cumulative dose of 3.5 and $5.35 \mathrm{mg} / \mathrm{kg}$ over the 96-week study, respectively). Treatment with 3.5 and 5.25 $\mathrm{mg} / \mathrm{kg}$ cladribine tablets significantly reduced the annualized relapse rate to Week 96 (relative reduction $57.6 \%$ and 54.5\% vs placebo, respectively, both $P<0.001$ ) and resulted in significantly more relapse-free patients at Week 96 (79.7\% and $78.9 \%$ vs $60.9 \%$, respectively; odds ratios: 2.53 and 2.43 , both $P<0.001) .{ }^{28}$ Three measures were detected: T1 gadolinium-enhancing lesions, active T2 lesions and combined unique lesions (all $P<0.001$ vs placebo). The results from CLARITY demonstrated that annual short-course dosing with cladribine tablets at both dosing regimens $(3.5 \mathrm{mg} / \mathrm{kg}$ and $5.25 \mathrm{mg} / \mathrm{kg}$ ) provided rapid and sustained improvements in clinical and MRI outcomes for patients with RRMS over the duration of the 96-week study (Table 2).

\section{Safety and tolerability}

The safety of cladribine has been well-known on the basis of wide experience acquired during years of study across different medical fields. Cladribine was generally well-tolerated in the individual Scripps studies in MS. ${ }^{29,30}$ In a pooled analysis of the data with cladribine vs placebo from the three Scripps studies and an additional supportive study in patients with MS, the most commonly reported treatment-emergent AEs were upper respiratory tract infections ( 32 vs $24 \%$ ), headaches ( 28 vs $38 \%$ ) and injection-site reactions ( 24 vs $25 \%))^{27}$ There was a small dose-related increase in the frequency of upper respiratory tract and urinary tract infections (UTIs). AEs reported more often with cladribine than placebo treatment were hypertonia; purpura, muscle weakness and upper respiratory tract infections. ${ }^{29}$ No serious adverse events (SAEs) related to cardiotoxicity, nephrotoxicity or neurotoxicity were reported in the Scripps studies, consistent with the observation in oncology patients. As expected from its mechanism of action, cladribine treatment significantly reduced the number of leukocytes in these studies. However the incidence of infections remained low, mainly comprising 
Table 2 CLARITY: Clinical and imaging end points and relapses during the 96-week study ${ }^{28}$

\begin{tabular}{|c|c|c|c|c|}
\hline Endpoint & Cladribine 3.5 mg/kg & Cladribine $5.25 \mathrm{mg} / \mathrm{kg}$ & Placebo & $P$ value \\
\hline \multicolumn{5}{|l|}{ Relapse } \\
\hline Annualized relapse rate over & 0.14 & 0.15 & 0.33 & $<\left.0.00\right|^{a, b}$ \\
\hline \multicolumn{5}{|l|}{96 weeks } \\
\hline Proportion of patients relapse & $79.7 \%$ & $78.9 \%$ & $60.9 \%$ & $<\left.0.00\right|^{a, b}$ \\
\hline \multicolumn{5}{|l|}{ free over 96 weeks } \\
\hline Time to first relapse, months & 13.4 & 13.3 & 4.6 & $<\left.0.00\right|^{a, b}$ \\
\hline \multicolumn{5}{|l|}{ Disability } \\
\hline Risk of 3-month sustained disability & $0.67[0.49,0.96]$ & $0.69[0.48,0.93]$ & & $0.018^{\mathrm{a}}$ \\
\hline progression on EDSS: Hazard & & & & $0.026^{\mathrm{a}}$ \\
\hline \multicolumn{5}{|l|}{ ratio vs placebo, $[95 \% \mathrm{Cl}]$} \\
\hline \multicolumn{5}{|l|}{ Magnetic resonance imaging } \\
\hline Mean number of TI Gd+ lesions & 0.12 & 0.11 & 0.91 & $<\left.0.00\right|^{a, b}$ \\
\hline \multicolumn{5}{|l|}{ per subject per scan over 96 weeks } \\
\hline Relative reduction in mean number & $85.7 \%$ & $87.9 \%$ & & \\
\hline \multicolumn{5}{|l|}{ of $\mathrm{TI} \mathrm{Gd}+$ lesions relative } \\
\hline \multicolumn{5}{|l|}{ to placebo over 96 weeks } \\
\hline Mean number of active $\mathrm{T} 2$ lesions & 0.35 & 0.29 & 1.38 & $<\left.0.00\right|^{a, b}$ \\
\hline \multicolumn{5}{|l|}{ per subject per scan over 96 weeks } \\
\hline Relative reduction in mean number & & $73.4 \%$ & $76.9 \%$ & \\
\hline \multicolumn{5}{|l|}{ of active $\mathrm{T} 2$ lesions relative } \\
\hline \multicolumn{5}{|l|}{ to placebo over 96 weeks } \\
\hline Mean number of $\mathrm{CU}$ lesions per subject & 0.39 & 0.33 & 1.65 & $<\left.0.00\right|^{a, b}$ \\
\hline \multicolumn{5}{|l|}{ per scan over 96 weeks } \\
\hline Relative reduction in mean number of active & & $74.4 \%$ & $77.9 \%$ & \\
\hline CU lesions relative to placebo over 96 weeks & & & & \\
\hline
\end{tabular}

Notes: ${ }^{\mathrm{a}} 3.5 \mathrm{mg} / \mathrm{kg}$ dosage; ${ }^{\mathrm{b}} 5.25 \mathrm{mg} / \mathrm{kg}$ dosage.

Abbreviations: $\mathrm{CU}$, combined unique; EDSS, expanded disability status scale; Gd+, gadolinium-enhancing.

UTIs and herpes zoster reactivation, and overall was similar between patients treated with cladribine or placebo. ${ }^{30}$ Parenteral cladribine has been shown to be teratogenic in mice and rabbits, but its effects on human fertility and development are not known. Parental cladribine is not recommended for use by pregnant women, and adequate contraceptive precautions should be taken by patients of child-bearing age receiving cladribine treatment.

The safety profile of cladribine tablets in the CLARITY study, was as expected from the Scripps studies and its mechanism of action. Lymphopenia occurred more frequently in patients treated with cladribine tablets at both dosages than with placebo $(21.6 \%, 31.5 \%$ vs $1.8 \%$ patients, respectively). ${ }^{28}$ Despite the lymphopenia observed in cladribine-treated patients, the overall incidence of infections was similar across treatment groups: infections or infestations were reported in $47.7 \%$ of the patients in the cladribine $3.5-\mathrm{mg} / \mathrm{kg}$ group, $48.9 \%$ in the cladribine $5.25 \mathrm{-mg} / \mathrm{kg}$ group, and $42.5 \%$ in the placebo group, with most of the events graded as mild or moderate by investigators $(99.6 \%$ and $98.6 \%$, respectively, vs $99.0 \%) .{ }^{26}$ There were no cases of herpes zoster in the placebo group compared with $8(1.9 \%)$ cases and $12(2.6 \%)$ cases of herpes zoster in the $3.5 \mathrm{mg} / \mathrm{kg}$ group and $5.35 \mathrm{mg} / \mathrm{kg}$ group respectively. However, all cases were dermatomal and self-limiting and there have been no reports of disseminated herpes zoster. ${ }^{28}$ The occurrence of neoplasms (benign, malignant, or unspecified) was reported as an SAEs in $1.4 \%$ of patients in the cladribine $3.5 \mathrm{-mg} / \mathrm{kg}$ group and in $0.9 \%$ of those in the cladribine $5.25-\mathrm{mg} / \mathrm{kg}$ group, as compared with no patients in the placebo group. ${ }^{28}$ On the basis of the small number of neoplasms, developed in different solid organs after relatively short intervals from treatment to diagnosis it is not possible to establish a risk due to the use of cladribine tablets. One patient treated with cladribine tablets had reactivation of latent tuberculosis and died. The use of cladribine may have contributed to this reactivation, and tuberculosis screening measures were immediately introduced subsequently in on-going trials.

\section{Ongoing clinical trials}

Following the completion of the CLARITY study, the 96-week CLARITY EXTENSION study is currently ongoing and will provide data on the long-term safety and efficacy of extended treatment with cladribine tablets in patients who completed the CLARITY study. This study will primarily provide further information on the longer-term safety and tolerability of cladribine tablets administered for an 
additional third and fourth year in patients with RRMS. The extension study will also provide an opportunity to evaluate the sustained effects of treatment after only four or six courses of cladribine tablets received in the prior 2 years of the CLARITY parent study. Patients originally randomized to placebo will receive cladribine tablets, whereas those originally randomized to cladribine will be rerandomized to either cladribine tablets or placebo. In addition to clinical endpoints, safety assessments will include hematological monitoring and liver function testing. ${ }^{31}$ Since many patients with MS are currently receiving DMD therapy but have suboptimal response, additional studies are needed to investigate the potential benefits and risks of adding a treatment such as cladribine tablets. This would also have the advantage of adding to our understanding of the additive efficacy of cladribine in terms of severity and frequency of relapse and improvements in MRI measures, relative to that obtained with established DMDs. It is hoped that this will be achieved from the ONWARD (Oral cladribine added oN to Rebif New Formulation in patients With Active Relapsing Disease) trial, comparing the addition of cladribine tablets or placebo to existing IFN $\beta$ therapy. The ONWARD trial is a 96-week, randomized, double blind, placebo-controlled, phase IIb trial in patients with active relapsing MS. This ongoing study will evaluate the safety and tolerability of oral cladribine tablets as an add-on therapy to IFN $\beta-1 \mathrm{a} .{ }^{32}$ The study will recruit 260 patients already receiving IFN $\beta$ (Rebif, Betaseron or Avonex) who have active relapsing MS, defined as $\geq 1$ relapse in the preceding 48 weeks. Cladribine tablets will be administered in short courses, as in the CLARITY study: once-daily for 4-5 consecutive days per month (28-day period). The study will evaluate as primary safety endpoints the proportion of patients developing grade 3 or 4 toxicity on selected hematology and liver function parameters, and incidence of infections. The primary efficacy endpoint is the mean change in the number of new T1 Gd-enhancing lesions per patient per scan from baseline to 96 weeks. Secondary endpoints include other MRI measures, relapse rate and disability progression. ${ }^{32}$

In order to support cladribine tablets as a first-line therapy another study will evaluate the efficacy and safety of monotherapy with cladribine tablets versus placebo to prevent conversion to clinically definite MS in patients with a first clinical demyelinating event at high risk of developing MS. ORACLE (ORAl CLadribine in Early MS) is a 96-week, randomized, double-blind, placebo-controlled, international trial involving more than 600 patients considered at risk of developing MS due to a recently-experienced isolated demyelinating event and having MRI brain scans consistent with early signs of MS. Study participants will be randomized to receive one of two different dosage regimens of cladribine tablets or matching placebo tablets (1:1:1). The primary endpoint of the ORACLE MS trial is time to conversion to MS, according to the McDonald criteria. Other endpoints include time to conversion to clinically definite MS according to the Poser criteria (the main secondary endpoint), assessments of MRI brain scans, and disability progression. ${ }^{33}$

\section{The importance of adherence}

Since MS is a currently incurable, chronic disease, long-term DMD therapy is required, which requires commitment from patients to continue their treatment indefinitely. Adherence is a primary determinate of the effectiveness of any treatment and poor adherence attenuates optimum clinical benefit. Poor or nonadherence to treatment has been recognized as a major problem in the healthcare system, and has been widely reported in a variety of disease states for both parenteral and oral medications. Poor adherence to prescribed medication is associated with increased patient morbidity, poorer quality of life, and increased financial strain on healthcare institutions. ${ }^{34}$ Maintaining adherence to DMDs is a daily challenge to those who manage and coordinate care for MS patients. Several reviews have estimated nonadherence rates in patients treated with DMDs, with results varying between $6 \%$ and $43 \%$. There are several possible explanations for this trend. Firstly all treatment benefits cannot be felt immediately and injectable therapy (along with their associated side effects) may be prescribed when the patient feels well, so many patients are reluctant to experience the side effects for a benefit that is yet to be observed. Other factors can also contribute to nonadherence conduct. In one study the most common reason listed by participants for missing treatment, was that they simply forgot to administer it (58\%). Others missed injections because they did not feel like taking the medication $(22 \%)$ or were tired of taking injections $(16 \%) \cdot{ }^{35}$ Nonadherent behavior is closely linked to factors directly related to the performance of injection therapy, such as being tired of taking injections, skin reactions, pain at injection sites, injection-related anxiety, reduced manual dexterity or cognitive impairment.

Flu-like syndrome is a common complaint, reported as a side effect more often by patients treated with IFN $\beta$ therapy than with glatiramer acetate. Amongst these side effects the most uncomfortable one, according to patients, is the flu-like syndrome they experience especially at the onset of the treatment. Patients may feel that the treatment interferes with other important aspects of daily life and consequently perceive their therapy in a negative way. 
It has been widely reported that patients who have more positive feelings towards prescribed therapy adhere more closely to their therapeutic regimen. The development of drugs with easier administration, such as oral agents, would further promote adherence. Patients express greater satisfaction with the convenience of oral therapies, and oral medications are known to be preferred to injected therapies that have similar efficacy. ${ }^{36,37}$

Furthermore patients prefer less-frequent dosing of oral therapy to more-frequent dose regimens. ${ }^{38}$ The introduction of therapies for MS that are more acceptable to the patient could increase the number of patients with this chronic progressive disease being treated, reducing discomfort and inconvenience, making it easier for patients to adhere to their treatment regimen and thus improving efficacy. ${ }^{39}$ Therefore, improved adherence will result in better treatment outcomes, reducing disability, morbidity and the economic burden on the healthcare system.

\section{Conclusions}

The availability of cladribine tablets to treat MS in the near future could present several advantages. Firstly, the improvement of adherence to treatment and quality of life of patients with MS. Secondly, the mechanism of action of cladribine suggests its suitability for use as a monotherapy and as combination therapy, leading to increased efficacy with acceptable safety for those patients who do not respond adequately to single-agent therapies.

Adherence to prescribed treatment is essential for optimal long-term efficacy of pharmacotherapies for chronic conditions such as MS.

Cladribine has a mechanism of action, pharmacokinetic profile and a lasting effect on lymphocyte populations that permits short-course dosing, requiring only 8-20 days of treatment each year. This short and intermittent dosing regimen is expected to have a positive impact on patients' adherence to therapy and quality of life.

The CLARITY study is designed to assess the use of cladribine tablets as first-line therapy for MS. However, their mode of action also makes cladribine tablets a potential candidate for use in combination with available DMDs. The use of drug combinations with synergistic mechanisms holds promise for enhanced therapeutic benefit and may allow avoidance of dose-limiting toxicity. Moreover, the short-course, intermittent dosing schedule of cladribine tablets is likely to be a convenient and acceptable regimen for use as an add-on therapy. As such, add-on treatment with cladribine tablets may be of benefit for patients experiencing breakthrough disease while receiving active treatment with an existing DMD. However, the potential for additional side effects and toxicity must be considered.

Safety is likely to become the most important factor in the future development of MS drugs. The safety of drug combinations will be crucial to future therapeutic decision-making and more research is also needed to compare escalation and induction treatment strategies.

\section{Disclosure}

The authors declare no conflicts of interest.

\section{References}

1. Murray TJ. Diagnosis and treatment of multiple sclerosis. $B M J$. 2006;332:525-527.

2. Lassmann H, Bruck W, Lucchinetti CF. The immunopathology of multiple sclerosis: an overview. Brain Pathol. 2007;17:210-218.

3. Weinshenker BG. The natural history of multiple sclerosis. Neurol Clin. 1995;13:119-146.

4. Lublin FD, Reingold SC. Defining the clinical course of multiple sclerosis: results of an international survey. National Multiple Sclerosis Society (USA) Advisory Committee on Clinical Trials of New Agents in Multiple Sclerosis. Neurology. 1996;46:907-911.

5. Kappos L, Freedman MS, Polman CH, et al. Effect of early versus delayed interferon beta- $1 \mathrm{~b}$ treatment on disability after a first clinical event suggestive of multiple sclerosis: a 3-year follow-up analysis of the BENEFIT study. Lancet. 2007;370:389-397.

6. Sbardella E, Tomassini V, Gasperini C, et al. Neutralizing antibodies explain the poor clinical response to interferon beta in a small proportion of patients with multiple sclerosis: a retrospective study. BMC Neurol. 2009;9:54.

7. Wingerchuk DM. Multiple sclerosis disease-modifying therapies: adverse effect surveillance and management. Expert Rev Neurother. 2006;6:333-346.

8. Linker RA, Kieseier BC, Gold R. Identification and development of new therapeutics for multiple sclerosis. Trends Pharmacol Sci. 2008;29:558-565

9. Kappos L, Antel J, Comi G, et al. Oral fingolimod (FTY720) in relapsing MS: 24-month results of the phase II study. $N$ Engl $J$ Med. 2006;355:1124-1140.

10. Kappos L, Radue EW, O'Connor P, et al. A placebo-controlled trial of oral fingolimod in relapsing multiple sclerosis. $N$ Engl $J$ Med. 2010;362:387-401.

11. Cohen JA, Barkhof F, Comi G, et al. Oral fingolimod or intramuscular interferon for relapsing multiple sclerosis. $N$ Engl J Med. 2010;362: 402-415.

12. Ockenfels HM, Schultewolter T, Ockenfels G, Funk R, Goos M. The antipsoriatic agent dimethylfumarate immunomodulates T-cell cytokine secretion and inhibits cytokines of the psoriatic cytokine network. Br J Dermatol. 1998;139:390-395.

13. Schimrigk S, Brune N, Hellwig K, et al. Oral fumaric acid esters for the treatment of active multiple sclerosis: an open-label, baseline-controlled pilot study. Eur J Neurol. 2006;13:604-610.

14. Kappos L, Gold R, Miller DH, Macmanus DG, et al. Efficacy and safety of oral fumarate in patients with relapsing-remitting multiple sclerosis: a multicentre, randomised, double-blind, placebo-controlled phase IIb study. Lancet. 2008;372:1463-1472.

15. Bruneau JM, Yea CM, Spinella-Jeagle S, et al. Purification of human dihydro-orotate dehydrogenase and its inhibition by A77 1726, the active metabolite of leflunomide. Biochem. 1998;J336:299-303.

16. Korn T, Toyka K, Hartung HP, Jung S. Suppression of experimental autoimmune neuritis by leflunomide. Brain. 2001;124:1791-1802. 
17. Korn T, Magnus T, Toyka K, Jung S. Modulation of effector cell functions in experimental autoimmune encephalomyelitis by leflunomide mechanisms independent of pyrimidine depletion. J Leukoc Biol. 2004; 76:950-960.

18. O'Connor PW, Li D, Freedmann MS, et al. A phase II study of the safety and efficacy of teriflunomide in multiple sclerosis with relapses. Neurology. 2006;66:894-900.

19. Yang JS, Xu LY, Xiao BG, Hedlund G, Link H. Laquinimod (ABR215062) suppresses the development of experimental autoimmune encephalomyelitis, modulates the Th1/Th2 balance and induces the Th3 cytokine TGF $\beta$ in Lewis rats. J Neuroimmunol. 2004;156:3-9.

20. Comi G, Pulizzi A, Rovaris M, et al. Effect of laquinimod on MRImonitored disease activity in patients with relapsing-remitting multiple sclerosis: a multicentre, randomised, double-blind, placebo-controlled phase IIb study. Lancet. 2008;371:2085-2092.

21. Carson DA, Wasson DB, Taetle R, Yu A. Specific toxicity of 2-chlorodeoxyadenosine toward resting and proliferating human lymphocytes. Blood. 1983;62:737-743.

22. Liliemark J. The clinical pharmacokinetics of cladribine. Clin Pharmacokinet. 1997;32:120-131.

23. Beutler E, Sipe JC, Romine JS, et al. The treatment of chronic progressive multiple sclerosis with cladribine. Proc Natl Acad Sci USA. 1996;93:1716-1720.

24. Beutler E. New chemotherapeutic agent: 2-chlorodeoxyadenosine. Semin Hematol. 1994;31(1):40-45.

25. Rice GP, Filippi M, Comi G. Cladribine and progressive MS: clinical and MRI outcomes of a multicenter controlled trial. Cladribine MRI Study Group. Neurology. 2000;54:1145-1155.

26. Schirmer M, Mur E, Pfeiffer KP, Thaler J, Konwalinka G. The safety profile of low-dose cladribine in refractory rheumatoid arthritis. A pilot trial. Scand J Rheumatol. 1997;26:376-379.

27. Romine JS, Sipe JC, Koziol JA, Zyroff J, Beutler E. A double-blind, placebo-controlled, randomized trial of cladribine in relapsing-remitting multiple sclerosis. Proc Assoc Am Physicians. 1999;111:35-44.

28. Giovannoni G, Cook S, Comi G, et al; the CLARITY study group. A placebo controlled Trial of Oral Cladribine for Multiple Sclerosis. N Engl J Med. 2010 Jan 20. [Epub ahead of print].

29. Stelmasiak Z, Solski J, Nowicki J, Jakubowska B, Ryba M, Grieb P. Effect of parenteral cladribine on relapse rates in patients with relapsing forms of multiple sclerosis: results of a 2-year, double-blind, placebocontrolled, crossover study. Mult Scler. 2009;15(6):767-770.
30. Leist TP, Vermersch $P$. The potential role for cladribine in the treatment of multiple sclerosis: clinical experience and development of an oral tablet formulation. Curr Med Res Opin. 2007;23:2667-2676.

31. Rieckmann P, Giovannoni G, Cook SD, et al. Cladribine tablets in relapsing-remitting multiple sclerosis: study design of the 2-year, Phase IIIb CLARITY (CLAdRibine tablets Treating multiple sclerosis orallY) extension study. Mult Scler. 14:S161-S162.

32. Viglietta V, Greenberg S, Mikol D, et al. Clinical development plan for cladribine tablets, an oral immunomodulator, for the treatment of multiple sclerosis (Meeting Abstract, Annual Congress of European Committee for Treatment and Research in Multiple Sclerosis [ECTRIMS], Dusseldorf, Germany, 2009 Sep 9-12). [P439]. Mult Scler. 15;S126-S127 (2009).

33. Merck Serono (2009) Merck Serono Announces Initiation of the ORACLE MS Trial to Evaluate Cladribine Tablets in Patients at Risk of Developing Multiple Sclerosis. Press release 2008-10-31. http:// www.merckserono.net/corp.merckserono/en/images/20070124_en_ tcm112_16812.pdf?Version=

34. Di Matteo MR. Variations in patients' adherence to medical recommendations: a quantitative review of 50 years of research. Med Care. 2004;42:200-209.

35. Klauer T, Zettl UK. Compliance, adherence, and the treatment of multiple sclerosis. J Neurol. 2008;255 Suppl 6:87-92.

36. Cohen BA, Rieckmann P. Emerging oral therapies for multiple sclerosis. Int J Clin Pract. 2007;61:1922-1930.

37. Fallowfield L, Atkins L, Catt S, et al. Patients' preference for administration of endocrine treatments by injection or tablets: results from a study of women with breast cancer. Ann Oncol. 2006;17:205-210.

38. Twelves C, Gollins S, Grieve R, Samuel L. A randomised crossover trial comparing patient preference for oral capecitabine and 5-fluorouracil/ leucovorin regimens in patients with advanced colorectal cancer. Ann Oncol. 2006;17:239-245.

39. Kruk ME, Schwalbe N. The relation between intermittent dosing and adherence: preliminary insights. Clin Ther. 2006;28:1989-1995.
Therapeutics and Clinical Risk Management

\section{Publish your work in this journal}

Therapeutics and Clinical Risk Management is an international, peerreviewed journal of clinical therapeutics and risk management, focusing on concise rapid reporting of clinical studies in all therapeutic areas, outcomes, safety, and programs for the effective, safe, and sustained use of medicines. This journal is indexed on PubMed Central, CAS,

\section{Dovepress}

EMBase, Scopus and the Elsevier Bibliographic databases. The manuscript management system is completely online and includes a very quick and fair peer-review system, which is all easy to use. Visit http://www.dovepress.com/testimonials.php to read real quotes from published authors. 